\title{
Uniting science and stories: Perspectives on the value of storytelling for communicating science
}

\author{
Stephanie J. Green ${ }^{a \star \dagger}$, Kirsten Grorud-Colvert ${ }^{b \dagger}$, and Heather Mannix ${ }^{c \dagger}$ \\ ${ }^{a}$ Center for Ocean Solutions, Stanford University, 99 Pacific Street, Suite 555E, Monterey, CA 93940, \\ USA; ${ }^{b}$ Department of Integrative Biology, Oregon State University, 3029 Cordley Hall, Corvallis, \\ OR 97331, USA; 'COMPASS, 8720 Georgia Ave, Ste. 803. Silver Spring, MD 20910, USA \\ *steph.j.green@gmail.com \\ ${ }^{\dagger}$ All authors contributed equally to this work and are listed alphabetically.
}

OPEN ACCESS

Citation: Green SJ, Grorud-Colvert K, and Mannix H. 20I8. Uniting science and stories: Perspectives on the value of storytelling for communicating science. FACETS 3: 164-173. doi: 10.1 | 39/facets-2016-0079

Handling Editor: Marie-Claire Shanahan

Received: December 31, 2016

Accepted: November 3, 2017

Published: February 21, 2018

Copyright: (c) 2018 Green et al. This work is licensed under a Creative Commons

Attribution 4.0 International License (CC BY 4.0), which permits unrestricted use, distribution, and reproduction in any medium, provided the original author(s) and source are credited.

Published by: Canadian Science Publishing

\begin{abstract}
Science helps us identify problems, understand their extent, and begin to find solutions; it helps us understand future directions for our society. Scientists bear witness to scenes of change and discovery that most people will never experience. Yet the vividness of these experiences is often left out when scientists talk and write about their work. A growing community of practice is showing that scientists can share their message in an engaging way using a strategy that most are already familiar with: storytelling. Here we draw on our experiences leading scientist communication training and hosting science storytelling events at the International Marine Conservation Congress to share basic techniques, tips, and resources for incorporating storytelling into any scientist's communication toolbox.
\end{abstract}

Key words: science communication, storytelling, story shapes

\section{Why tell stories about science?}

Scientists have witnessed firsthand the effects of global warming on melting sea ice. Some have felt the thrill of discovering a new genetic marker that could hold the key to understanding a disabling disease. Others have surveyed piles of hunted bushmeat contributing to the decline of mammals around the globe, and they have seen the perils of food insecurity facing the communities who hunt these mammals. Some have watched giddily as spawning corals release millions of tiny white eggs in a single night only to see those same animals later bleach stark white when stressed by higher-than-ever ocean temperatures. Whether in the field, in the lab, or analyzing data on our computer screens, scientists bear witness to changes and discoveries that most people will never experience. Yet the training that scientists receive typically does not focus on communicating these vivid experiences in a way that is engaging to nonscientist audiences.

From the beginning, scientists are trained to communicate research conducted via the scientific method. This approach typically focuses on testing succinct hypotheses by developing and executing methods, analyzing data, and presenting results in a way that builds on existing knowledge and, ideally, spurs discussion among peers (Baron 2010; Sharon and Baram-Tsabari 2014). Among the norms and practices of doing science is that of "disinterestedness" (Merton 1973; National Academies of Sciences, Engineering, and Medicine 2009), where scientists act for the benefit of a common scientific enterprise rather than for personal gain (Merton 1973). Disinterested scientists 
may establish credibility and authority (Merton 1973). However, the scientific process and the norms that guide it contribute to an intentionally prosaic, impersonal, and precise way of writing about scientific discoveries (Sand-Jensen 2007), which are typically packaged in a scientific paper and subjected to the peer-review process. As with any form of communication, the language of science is useful for talking to people who speak the same dialect: other scientists (Sharon and BaramTsabari 2014).

Yet a growing number of scientists assert that sharing discoveries within the scientific community is not enough (e.g., Lubchenco 1998; Posner et al. 2016). This is because science helps us understand future directions for our society as it identifies problems and potential solutions; scientific discoveries are therefore most impactful when shared broadly with those who can implement solutions and enact change (Posner et al. 2016). Thus, the public funding received by most scientists comes with a responsibility (i.e., a "social contract") to address urgent societal needs through research and to communicate findings broadly with "good judgment, wisdom, and humility" (Lubchenco 1998). Nonscientists far outnumber scientists in society. It is no surprise, then, that the detached and technical way in which scientists describe their research contributes to the perception of scientists as competent (i.e., worthy of respect due to their expertise) but also "cold" - and as a result, less likely to be trusted (Fiske and Dupree 2014). Although the scientific method provides a means for competently producing information, as scientists we must find other forms of communication to fulfil our social contract.

This is where we have the opportunity to return the vividness of personal experiences to our science. Neuroscience research has shown that using metaphors based on sight, smell, sound, or taste also activates the sensory areas of the brain's cortex as opposed to solely the language-processing areas of the brain that are activated when listeners process literal sentences (Lacey et al. 2012). When participants of the study listened to prerecorded narrative stories told in front of a live audience in an engaging style and with rich detail, brain activity in the cerebral cortex indicated strong response to narrative stimuli as opposed to short words or phrases (Huth et al. 2016). Even more impressively, research on brain-to-brain coupling has shown that speakers' and listeners' brains exhibit jointly coupled response patterns (Stephens et al. 2010). When we describe experiences vividly for others, the listener's brain lights up along with ours - as if we had all experienced the same events (Hasson et al. 2012). Indeed, the rich body of literature on narrative transportation - the ability of a story to mentally transport its listener into the storyteller's world-supports the link between a strategically constructed story and its ability to persuade its listener (e.g., Green and Brock 2000; van Laer et al. 2014).

So what are the opportunities to bring people into our science through stories? Where do we start learning this language? The good news is that most scientists are naturally bilingual-we do more than talk to other scientists all day. At some point we leave the lab or the clinic or the field site and interact with other people (nonscientists!) at the grocery store, while visiting our neighbors and friends, or sharing a meal with family. During these interactions, we might meet someone who asks, "What do you do?" Do we use the language of science to respond? Most likely we would prefer to speak in a way that builds connection with our listener and creates excitement about what our science tells us. We can do this by telling a story.

We all know someone who is a good storyteller. They can liven up a party or a long car ride, drawing you in with humor or sometimes melancholy, but they always pull you out of your current surroundings and into their world and evoke an emotional response. As scientists, we also write summaries of our research results and identify the bottom line (i.e., the "take-home message"). Can we weave that bottom line into a story, where our listeners are vicariously experiencing what we have done and seen, sharing in our discoveries and the changes we have witnessed? Can we perhaps even change the way our listener or reader sees the world based on our science? 
A growing community of practice is demonstrating that scientists can use storytelling techniques and types to broadly share their message in a way that has lasting impact on nonscientist listeners and readers (Krzywinski and Cairo 2013; Leslie et al. 2013; Dahlstrom 2014; Kelly et al. 2014; Erickson and Ward 2015; and see the "Adding storytelling to your science communication tool box" section). Our experience comes from three years of training scientists in storytelling and facilitating live science storytelling events at the International Marine Conservation Congress (IMCC), an international meeting of marine scientists and practitioners held every two years. The genesis of this project was our own experience as scientists and science communicators seeking to explore how our research can help address societal problems. In 2013, we pooled our collective training, knowledge, and enthusiasm for science communication and developed a two-day intensive workshop on science storytelling delivered at IMCC in 2014 and 2016. We paired these workshops with an opportunity for participants to share their stories live with a public audience during the meeting (Fig. 1). Our goals for these efforts were three-fold: (1) broaden the reach of the scientific research presented at international conferences like IMCC by increasing interaction between members of the public and the scientists who attend, (2) build scientists' skillset to develop and share key scientific discoveries and experiences through compelling oral stories, and (3) build a digital library of scientists' stories that serves as a tool for learning about science and conservation and as examples for other scientists who are developing these communication skills. To date, 19 scientists from nearly a dozen countries have participated in the IMCC "Tales from the Sea" workshops, resulting in 18 story videos archived on the Society for Conservation Biology's (n.d.) website (conbio.org/groups/sections/marine/stories/). Here we share insights gained from facilitating the learning process for these scientist storytellers, with the aim of summarizing basic techniques and resources (Fig. 1). Although our examples are largely from marine science and conservation, these lessons are applicable across science disciplines and are helpful for incorporating storytelling into any science communication toolbox.

\section{Telling a (science) story}

Where do you start when developing a science story? It begins with the same elements that are key to any other type of story, including characters, setting, plot, outcome, and resolution (Bower 1976), all of which are essential for creating drama (Erickson and Ward 2015). Drama is a sequence of events

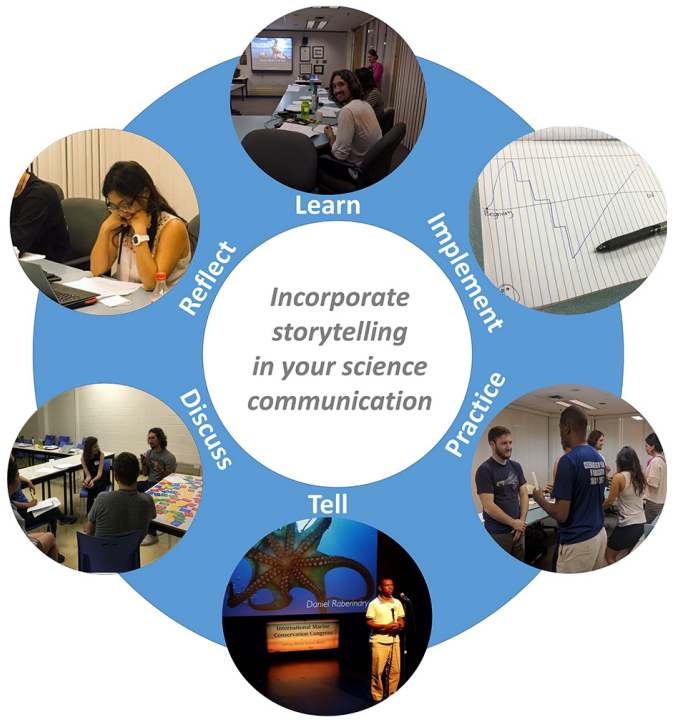

Fig. 1. The process of developing a science story using examples from a science storytelling training and live storytelling event at the International Marine Conservation Congress in July 2016. Scientist storytellers gained storytelling skills by learning and practicing techniques and developing a personal science story. 
created when a story's character encounters and resolves a problem. The character's actions (the "what") are motivated by the consequences they face if the problem is not resolved (the "why"). As we share lessons and experiences from our work, it isn't necessarily what we've done that is the key to a good story-it's why we did it. If we want to share key science messages, where we place these facts in our narrative can also strategically affect our listener's acceptance of this information (see the body of work on narrative causality and narrative persuasion, e.g., Green and Brock 2000; Dahlstrom 2010).

What is at stake in your science? An audience is more likely to connect and "buy into" your story when they empathize with the risk your character faces (e.g., van Laer et al. 2014). The rise and fall of emotion that your audience feels as the fortunes of your character change is what makes the journey a relatable story, rather than an exposition of events and facts (Erickson and Ward 2015). In fact, research shows that the drama a character experiences tracks a defined and quantifiable emotional arc (Reagan et al. 2016). American author Kurt Vonnegut illustrates the importance of drama and a problem/resolution pair in stories using a simple method that is sure to speak to scientists; he plots the fortune of a character over the course of his or her story (Swanson 2015; Fig. 2). A good story is never static, but instead progresses over time, with highs and lows that track the character's experiences in the unfolding drama (Reagan et al. 2016). Any story can be plotted (from Cinderella to Harry Potter) to show that (1) the fortunes of the main character change as the result of a major problem they face and (2) the story nearly always ends with a resolution to the problem-typically resulting in good fortune for the main character (Figs. $2 b-2 d$ ). If there is no change in fortune-no dramathen it is not a story (Fig. 2a).

Telling a story with a problem that needs solving may sound simple, but as scientists identifying sources of drama (i.e., problem/resolution pairs) can be challenging. In our experience this is at least in part because it can be hard to identify the main character. Often (but not always) scientists are at the center of their stories. The drama (i.e., problem/resolution) could also center on someone you

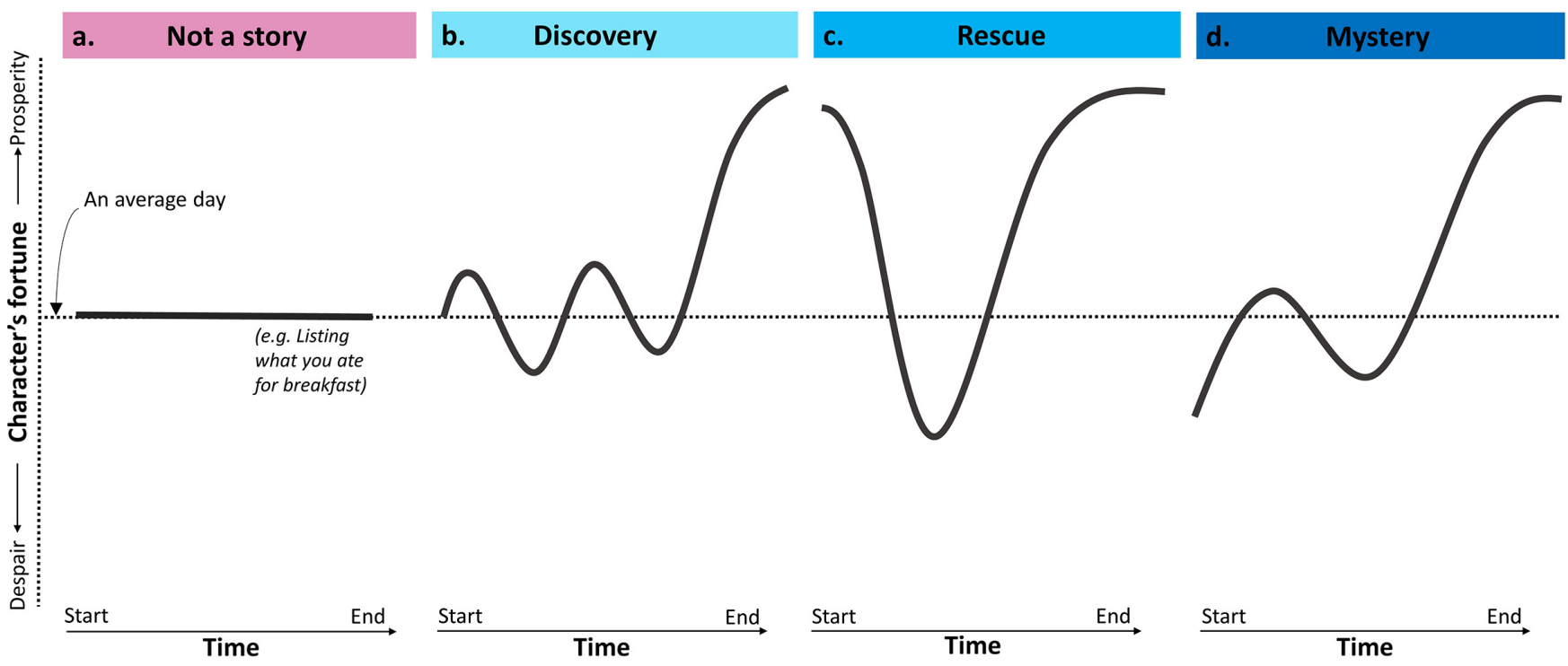

Fig. 2. The relative shapes of select paradigms for science stories. Solid black lines show the relationship between the main character's fortune and the progression of a story from start to finish, relative to an average day (dotted line). A good story needs a character that experiences both highs and lows, moving from despair to prosperity. 
work with, someone who is affected by the outcome of your research, or even your research subject itself (for example, a biologist's focal organism). Identifying the main character that experiences the risk of failure is essential - this character is the lens through which your audience experiences your story's drama. Important questions to ask as you think about developing stories from your research are: Who are the key characters that I work with? Am I the main character? What problems do they/I face in the course of this work? What is at risk if these challenges are not overcome? How is the problem resolved?

\section{Story shapes for science}

Several of the fellow scientists we worked with describe the process of developing stories as uncomfortable. It means digging up a habit long buried by careful training to focus on background content, methodology, and data. Yet scientists are on a mission to discover and explore; the process of generating science questions, conducting research, and framing our results is fraught with conflict, challenge, risk, failure, emotion-and often success and discovery. Research following the scientific method naturally contains many problem/resolution pairs. The challenge is picking these out and polishing them up. Thinking about your experience in relation to some common story paradigms that follow a particular shape can be a good starting place.

\section{Shape 1: Discovery}

Discovery is at the very essence of science-and also good stories. As scientists our method revolves around asking questions and discovering answers. The process leading up to that discovery is key. Often in stories of science discovery, scientists are the central characters. The listener invests in our well-being as we take them on a journey through the successes and failures (ups and downs, Fig. $2 \mathrm{~b}$ ) of our experiments, analyses, or field experiences. This process builds tension and expectation as we move closer to a discovery. The key to this type of story is that the result of these experiences (i.e., our discovery) is unexpected, increasing our overall understanding in ways we could not have imagined at the outset (the peak of the storytelling trajectory, Fig. 2b). What is the question you sought to answer? How do the actions you take to answer the question involve ups and downs or successes and failures? What is your discovery at the end, and how was it different from what you thought you might find? How did the discovery leave you better off than before? Why is it important? A recent story told by Matthew Tietbohl, who also participated in the IMCC 2016 workshop, shows how immersion in nature can inspire discovery (youtube.com/watch?v=QQWcinVN0a8). For Tietbohl, his passion for making discoveries as a child in Pennsylvania translates to a new way of discovering ecosystems in Jamaica and Saudi Arabia. Although his different set of expectations led him to a story low after undertaking challenging fieldwork, his discoveries led him to a greater understanding and a desire to share the importance of protecting habitats both muddy and marine.

\section{Shape 2: Rescue}

Science in service to society operates on the core tenet that the outcome of research should be solutions to major challenges that we face-as individuals, communities, nations, or a global community. Enter one of the most popular storytelling paradigms: a hero to the rescue (Fig. 2c). Whether it's finding a more efficient way to grow crops, developing genetic barcoding that prevents mislabeling and food piracy, or discovering a way to protect aquaculture from the effects of an acidifying ocean (e.g., Kelly et al. 2014), problem-solving research has the potential to rescue and restore (Fig. 2c). The key to this story's progression is that the audience steps into the story at a high point in the character's fortunes. They then experience a traumatic loss-followed by a recovery aided by science-as the story unfolds (Fig. 2c). In an age of increasingly dire predictions about climate and environmental change, the power of stories with science solutions that inspire hope and action cannot be 
underestimated. One such story of hope is told by Skye Augustine, who explains how science is helping to resurrect ancient clam gardens and reconnect younger generations of First Nations people to an integral part of their cultural and environmental heritage (youtube.com/watch? $\mathrm{v}=w \mathrm{dWDZV} 1 \mathrm{fz} 28)$. Augustine's engaging and deeply personal description of her characters draws her listeners into these experiences and her science.

\section{Shape 3: Mystery}

Often phenomena occur that we cannot readily explain, and there is much at stake-often for society-by not understanding how, why, and what has transpired. Part of what drives science is the desire to solve mysteries and uncover a new understanding of the world, leaving us at a story high (Fig. 2d). As scientists, we often play the role of "detective", as we carefully test alternative hypotheses and follow leads to discover why a phenomenon has transpired. We can't be certain of what we will find. A mystery is different from a discovery or rescue paradigm because the story begins in a different point of the character's fortune. In a mystery, we step into the story at a low point, where an event of unknown origin or cause has transpired, creating ill fortune for the main character (Fig. 2d). Drawing out your attempts to resolve the unknown-and the successes and failures that come along the way as you test out different theories-is a powerful way to engage your listeners to care about the outcome of the story (Fig. 2d). For example, when Kyle Gillespie begins at low on the story trajectory by setting out to better understand the life of invertebrates on coral reefs in the Philippines (Fig. 2d), his positive progress towards data collection is challenged by what appears to be a dead end in his fieldwork. Yet this seemingly negative experience helps Gillespie uncover the mysterious whereabouts of these creatures (youtube.com/watch? $\mathrm{v}=\mathrm{qCCehR}-\mathrm{mW0A} \&$ feature=youtu.be). His words paint a vivid picture of his search for species on a dark reef and ties this to his personal search for an elusive answer-a quest that resonates with many people.

\section{Lessons and tips for developing a science story}

Using storytelling to talk about science can be challenging, especially when it contrasts with the norms of scientific training. The storytelling workshop and training materials delivered at IMCC in 2014 and 2016 were designed to help scientists transform their knowledge, experiences, and insights into narratives and stories that can be shared with and appreciated by nonscientists. This transformation took place over two days, during which participants moved outside their comfort zones to brainstorm, develop, and tell stories. The training is grounded in research from the field of science communication using a combination of lecture, hands-on activities, practice, and feedback for each participant to develop his or her own $\sim 5$-min story. After the workshop, participants tell their stories to a live audience of other scientists and nonscientist community members, and the stories are filmed and posted to a growing online archive. Using a few common issues experienced by the participants, we offer strategies for working through several of the challenges of science storytelling.

\section{Identify your take-home message first}

Start with the end in mind. Think about what you want people to know about your work-perhaps your ongoing research study or an important breakthrough. You may want others to understand why or how you came to your area of research. Science storytelling is about more than simply telling a good story - the goal is to share a science message. Think in terms of the "so what". Ask why does this matter? Why would my audience care? A tool like the Message Box (COMPASS n.d.) can be helpful for identifying who to reach and what to say (Baron 2010). Based on practical experience and the scientific underpinnings of effective communication (National Academies of Sciences, Engineering, and Medicine 2017), the five sections of the Message Box help you sort and distill your knowledge in a way that resonates with your audience (COMPASS n.d.). Often, the message is the resolution, creating a clear path to map the rest of a story. 


\section{Remember the shape of your story}

Knowing your take-home message can help identify the conflict or struggle that will be resolved as the story progresses. This is essential for creating drama. Tracking the fortune of the main character over time in relation to the common story shapes outlined above can help identify the ups and downs (drama) and forward (timing) movement of the story (Fig. 2). The pacing of a narrative can determine whether a listener will invest in paying attention throughout the story.

\section{Consider the scale and timing of your story}

It can be tempting to start at the very beginning, but often compelling narratives tell small parts of a larger story. Reflect on which pieces might be unnecessary background. For example, process and methods, while very important to science, don't generally make a compelling story. Objectively consider whether the story loses movement towards the end. Keep the story moving, focusing on the main conflict and resolution as well as interesting characters, scenes, and action. Instead of a linear timeline, one strategy to capture a listener's attention is to begin with an exciting moment, return to an earlier point in time, and then build to the story's climax.

\section{Use vivid language}

Using vivid language helps the audience generate mental imagery and to feel as though they are experiencing the events in the story themselves (Green and Brock 2000; van Laer et al. 2014; Erickson and Ward 2015). Likewise, an in-depth description of a character can help listeners understand him or her, creating empathy and enabling the listener to "transport" through her or his imagination (van Laer et al. 2014). How many of the five senses-sight, smell, hearing, taste, and touchcan a story invoke? For example, during the workshop, we heard a description of falling rain during scientific fieldwork in the rainforests of Nicaragua. The storyteller brought her listeners into a humid and hot forest, where clothes stuck to backs and mosquitos buzzed incessantly against the netting a few inches from their faces. In our minds, we all scrambled for our ponchos as we felt the breeze pick up and heard the dull roar of the coming rain.

\section{Get feedback. Pause. Reflect. Try again.}

Feedback can be incredibly valuable when developing a good story. As with most things, any first attempt will be rough. Find a supportive and constructive friend or coworker and tell them your story in draft form. Get feedback about what didn't work and what resonated. Some helpful questions for asking or giving feedback include: What is my main message? Did I use jargon? Were there words or terms you didn't understand? Were there parts that dragged on or parts that I should explain further? Was the ending strong? Also practice self-evaluation. During the workshop we filmed each of the storytellers, who reflected on their nonverbal communication including posture, voice modulation, voice volume, and facial expressions.

\section{Discomfort and transformation}

Developing a new skill comes with its share of discomfort. In our experiences, scientist storytellers were challenged by their natural tendency to use jargon and to focus on process and methods. Yet as they practiced using vivid language, studied different story arcs, gave each other feedback, and focused on developing their message, the discomfort transformed into skill. Developing stories provided an opportunity for these scientists to explore their understanding of their own science and the scientific research of their fellow storytellers. All participants-regardless of age, career stage, or study system-developed a story that drew on this understanding and shared a message. 


\section{Adding storytelling to your science communication tool box}

Learning how to tell a good story is a process. As scientists who are sampling and conducting experiments in the lab and field, making small iterative changes to find the most effective process is part of our method. The same applies to storytelling, and there are many resources to assist. Weekly radio storytelling spots give a diversity of perspectives and storytelling styles, including those at NPR's Story Corps (storycorps.org/) and the science-focused podcasts from Radio Lab (radiolab.org/) and Story Collider (storycollider.org/). Many cities have live storytelling at open mic nights, including those at The Moth (themoth.org/) and Story District in Washington, DC (storydistrict.org/). Other opportunities for creative science storytelling also exist; for example, the Have We Got A Story To Tell series at the Royal B.C. Museum in Victoria, Canada (royalbcmuseum.bc.ca/visit/events/calendar/event/59461/ have-we-got-story-tell\%E2\%80\%94big-beasts), invites scientists to share their stories with museum guests against the backdrop of natural history displays depicting wild animals and human history. There are ample opportunities for training through organizations that are broadly focused on science communication; for example, Intermedia Communication Training (intermediacomms.com/), the Alan Alda Center for Communicating Science (centerforcommunicatingscience.org/), COMPASS (compassonline.org/), Story Circles (storycirclestraining.com/), Screenhouse (screenhouse.co.uk/ screenhouse_story_telling_course.html), and the Beakerhead Science Communicators Program (beakerhead.com/programs/scicomm) are among a growing list of groups that help scientists communicate their work through media-like storytelling.

It can be transformative to stand in front of a microphone and tell your story to a crowd, but most of us are more likely to use science storytelling in our day-to-day interactions. One of the best parts about storytelling is how easy it is to incorporate. Challenge yourself to use more vivid and descriptive language when talking about your science. Starting now, think up a story to tell to your friends at the next party you attend or consider beginning your next conference presentation with a story. Seek out the press office on your campus and ask for feedback on how you talk about your science. You can begin these strategies immediately to help hone your science story. People may see your work in a whole new light.

\section{Acknowledgements}

We are grateful to the team at COMPASS and Teresa Erickson and Tim Ward of Intermedia Communications for training and conversations that inspired this project. Erica Goldman helped to develop the science storytelling trainings and co-organize the first workshop-we are grateful for her insight during that process and on an earlier draft of this manuscript. Thanks also to Heather Reiff and Karmel James for their assistance with training coordination and media production. We also thank our partners in the Society for Conservation Biology's Marine Section-Samantha Oester, Edd Hind, Brett Favaro, and John Cigliano-for ongoing conversations about science storytelling and support for the live events cohosted at the IMCC conferences. Thanks to Nate Spillman for assistance with the SCB storytelling webpage design and construction and to Matthew Tietbohl and Katie Walters for assistance with video hosting. Special thanks to Canadian Science Publishing for cosponsoring the live storytelling event held in St. John's, Newfoundland in July 2016. This work was supported by a David H. Smith Conservation Research Fellowship (S.G.) and Banting Fellowship (S.G.) as well as funds from Oregon State University (K.G.C) and the David and Lucile Packard Foundation (H.M.).

\section{Author contributions}

SJG, KG-C and HM conceived and designed the study. SJG, KG-C and HM performed the experiments/collected the data. SJG, KG-C and HM analyzed and interpreted the data. SJG, KG-C and HM contributed resources. SJG, KG-C and HM drafted or revised the manuscript. 


\section{Competing interests}

The authors have declared that no competing interests exist.

\section{Data accessibility statement}

All relevant data are within the paper.

\section{References}

Baron N. 2010. Escape from the ivory tower: a researcher's guide to making your science matter. Island Press, Washington, D.C. 246 p.

Bower GH. 1976. Experiments on story understanding and recall. Quarterly Journal of Experimental Psychology, 28(4): 511-534. DOI: 10.1080/14640747608400579

COMPASS. n.d. The message box [online]: Available from compassscicomm.org/message-boxworkbook.

Dahlstrom MF. 2010. The role of causality in information acceptance in narratives: an example from science communication. Communication Research, 37(6): 857-875. DOI: 10.1177/009365021 0362683

Dahlstrom MF. 2014. Using narratives and storytelling to communicate science with nonexpert audiences. Proceedings of the National Academy of Sciences of the United States of America, 111(Suppl. 4): 13614-13620. PMID: 25225368 DOI: 10.1073/pnas.1320645111

Erickson T, and Ward T. 2015. Transformational storytelling. In The master communicator's handbook. Changemakers Books, Alresford, UK. 184 p.

Fiske ST, and Dupree C. 2014. Gaining trust as well as respect in communicating to motivated audiences about science topics. Proceedings of the National Academy of Sciences of the United States of America, 111: 13593-13597. PMID: 25225372 DOI: 10.1073/pnas.1317505111

Green MC, and Brock TC. 2000. The role of transportation in the persuasiveness of public narratives. Journal of Personality and Social Psychology, 79(5): 701-721. PMID: 11079236 DOI: $10.1037 /$ 0022-3514.79.5.701

Hasson U, Ghazanfar AA, Galantucci B, Garrod S, and Keysers C. 2012. Brain-to-brain coupling: a mechanism for creating and sharing a social world. Trends in Cognitive Sciences, 16(2): 114-121. PMID: 22221820 DOI: 10.1016/j.tics.2011.12.007

Huth AG, de Heer WA, Griffiths TL, Theunissen FE, and Gallant JL. 2016. Natural speech reveals the semantic maps that tile human cerebral cortex. Nature, 532(7600): 453-458. PMID: 27121839 DOI: $10.1038 /$ nature17637

Kelly RP, Cooley SR, and Klinger T. 2014. Narratives can motivate environmental action: the Whiskey Creek ocean acidification story. Ambio, 43(5): 592-599. PMID: 24081705 DOI: 10.1007/s13280013-0442-2

Krzywinski M, and Cairo A. 2013. Points of view: storytelling. Nature Methods, 10(8): 687. PMID: 24058975 DOI: 10.1038/nmeth.2571 
Lacey S, Stilla R, and Sathian K. 2012. Metaphorically feeling: comprehending textural metaphors activates somatosensory cortex. Brain and Language, 120(3): 416-421. PMID: 22305051 DOI: 10.1016/j. bandl.2011.12.016

Leslie HM, Goldman E, Mcleod KL, Sievanen L, Balasubramanian H, Cudney-Bueno R, et al. 2013. How good science and stories can go hand-in-hand. Conservation Biology, 27(5): 1126-1129. PMID: 23692176 DOI: 10.1111/cobi.12080

Lubchenco J. 1998. Entering the century of the environment: a new social contract for science. Science, 279(5350): 491-497. DOI: 10.1126/science.279.5350.491

Merton RK. 1973. The sociology of science: theoretical and empirical investigations. University of Chicago Press, Chicago, Illinois. 636 p.

National Academies of Sciences, Engineering, and Medicine. 2009. On being a scientist: a guide to responsible conduct in research: third edition. National Academies Press (US), Washington, D.C.

National Academies of Sciences, Engineering, and Medicine. 2017. Communicating science effectively: a research agenda. National Academies Press (US), Washington, D.C.

Posner SM, McKenzie E, and Ricketts TH. 2016. Policy impacts of ecosystem services knowledge. Proceedings of the National Academy of Sciences of the United States of America, 113(7): 1760-1765. PMID: 26831101 DOI: 10.1073/pnas.1502452113

Reagan AJ, Mitchell L, Kiley D, Danforth CM, and Dodds PS. 2016. The emotional arcs of stories are dominated by six basic shapes. EPJ Data Science, 5(1): 31. DOI: 10.1140/epjds/s13688-016-0093-1

Sand-Jensen K. 2007. How to write consistently boring scientific literature. Oikos, 116: 723-727. DOI: $10.1111 / \mathrm{j} .0030-1299.2007 .15674 . \mathrm{x}$

Sharon AJ, and Baram-Tsabari A. 2014. Measuring mumbo jumbo: a preliminary quantification of the use of jargon in science communication. Public Understanding of Science, 23(5): 528-546. PMID: 23825277 DOI: 10.1177/0963662512469916

Society for Conservation Biology. n.d. Conservation stories [online]: Available from conbio.org/ groups/sections/marine/stories/.

Stephens GJ, Silbert LJ, and Hasson U. 2010. Speaker-listener neural coupling underlies successful communication. Proceedings of the National Academy of Sciences of the United States of America, 107(32): 14425-14430. PMID: 20660768 DOI: 10.1073/pnas.1008662107

Swanson A. 2015. Kurt Vonnegut graphed the world's most popular stories [online]: Available from washingtonpost.com/news/wonk/wp/2015/02/09/kurt-vonnegut-graphed-the-worlds-most-popularstories/.

van Laer T, de Ruyter K, Visconti LM, and Wetzels M. 2014. The Extended Transportation-Imagery Model: a meta-analysis of the antecedents and consequences of consumers' narrative transportation. Journal of Consumer Research, 40(5): 797-817. DOI: 10.1086/673383 